\title{
EFEKTIVITAS PENGOBATAN SCABIES PADA KAMBING PERANAKAN ETTAWA DENGAN METODE SUBKUTAN DAN TOPIKAL
}

\section{The Effectiveness of Scabies Treatment in Ettawa Goats by Subcutan and Topical Methods}

\author{
Yusky Bagus Septiawan ${ }^{1}$ dan Suci Wulandari ${ }^{1}$ \\ ${ }_{1}^{1}$ Program Studi Produksi Ternak, Jurusan Peternakan, Politeknik Negeri Jember \\ Email: yuskiseptiawan@gmail.com
}

\begin{abstract}
ABSTRAK
Penelitian ini bertujuan untuk mengetahui efektivitas pengobatan terhadap kambing Peranakan Ettawa yang terserang scabies. Scabies merupakan penyakit kulit yang disebabkan infestasi tungau Sarcoptes scabiei. Gejala klinis ditandai dengan radang pada kulit dengan disertai keropeng dan bulu rontok pada daerah kulit yang terserang. Sampel yang digunakan adalah kambing Peranakan Ettawa masing-masing 5 ekor untuk setiap metode pengobatan. Metode pengobatan yang digunakan adalah metode subkutan atau penyuntikan dibawah kulit dan metode topikal yang dilakukan dengan cara menggosok obat pada bagian kulit. Obat yang digunakan dalam metode subkutan adalah Ivomec yang diinjeksikan setiap 10 hari sekali dengan dosis $0,025 \mathrm{ml}$ per bobot badan. Metode topikal menggunakan obat $V$-Traz yang digosokkan pada area kulit yang terinfeksi setiap 1 minggu sekali dengan dosis $10 \mathrm{ml} \mathrm{V-Traz} \mathrm{yang} \mathrm{dihomogenkan} \mathrm{dengan} \mathrm{1,250} \mathrm{ml}$ air. Data yang diperoleh dianalisis secara deskriptif. Hasil pengobatan menunjukkan kambing yang diobati menggunakan Ivomec membutuhkan waktu untuk penyembuhan selama 20 hari atau 2 kali pengobatan, sedangkan pengobatan dengan $V$-Traz membutuhkan 4 kali pengulangan pengobatan dengan total waktu penyembuhan 28 hari.
\end{abstract}

Kata kunci: Efektivitas, Ivomec, Sarcoptes scabiei, Scabies, V-Traz

\begin{abstract}
This study aims to determine the effectiveness of treatment for Ettawa Crossbreed goats attacked by scabies. Scabies is a skin disease caused by an infestation of the Sarcoptes scabiei mite. Clinical symptoms are characterized by inflammation of the skin accompanied by scabs and hair loss on the affected skin area. The sample used was 5 Ettawa Crossbred goats for each treatment method. The treatment used was the subcutaneous method or injection under the skin and the topical method which was done by rubbing the drug on the skin. The drug used in the subcutaneous method was Ivomec which was injected once every 10 days at a dose of $0.025 \mathrm{ml}$ per body weight. The topical method of the drug used was V-Traz which was rubbed on the infected skin area once a week with a dose of $10 \mathrm{ml} \mathrm{V-Traz}$ homogenized with 1,250 ml of water. The data obtained were analyzed descriptively. The results showed that the goats treated using Ivomec experienced hair loss and scabs that healed for 20 days or 2 treatments, whereas treatment by $V$-Traz required 4 repetitions of treatment with a total healing time of 28 days.
\end{abstract}

Keywords: Effectiveness, Ivomec, Sarcoptes scabiei, Scabies, V-Traz

\section{PENDAHULUAN}

Penyakit scabies atau kudis merupakan penyakit kulit menular (zoonosis) yang disebabkan oleh infeksi tungau Sarcoptes scabiei. Penyakit ini sering menimbulkan masalah kesehatan pada kambing yang terinfeksi seperti pertambahan berat badan menurun, merusak kulit, menular pada 
manusia dan mengakibatkan kematian terutama dalam kasus yang parah (Ginting, 2010). Penyakit scabies tersebut dikarenakan kurangnya tindakan penanganan pada kambing yang terinfeksi seperti sanitasi kandang, pemberian obat dan minimnya jumlah kandang karantina sehingga penyakit ini cepat menyebar dan menginfeksi kambing yang lain. Upaya yang dilakukan dalam mempercepat pengobatan penyakit ini dan mencegah percepatan penularan, yaitu dengan jenis obat akarisida yang diaplikasikan dalam berbagai rute baik subkutan maupun topikal (Cholilurachman, 2012). Beberapa akarisida yang biasa digunakan oleh praktisi adalah Amitraz, Ivermectin dan sejenisnya.

\section{METODE}

Pengobatan scabies ini menggunakan hewan percobaan kambing Peranakan Ettawa yang berumur 4 bulan masing-masing 5 ekor untuk setiap metode pengobatan. Kode ternak pada setiap kambing dicatat untuk membedakan metode pengobatan yang digunakan. Alat dan bahan yang digunakan adalah spuit $1 \mathrm{~mL}$, kapas, botol plastik, obat Ivomec yang mengandung Ivermectin 1\% dan clorunsol 10\%, alkohol, betadine dan obat V-Traz yang mengandung Amitraz 12,5\%. Metode pengobatan yang dilakukan yaitu metode subkutan dan topikal. Pengobatan metode subkutan dilakukan dengan injeksi antiparasit Ivomec dengan dosis $0,025 \mathrm{~mL} / \mathrm{kg}$ bobot badan ternak dengan cara subkutan. Prosedur pengobatan pada metode subkutan yaitu dengan menimbang ternak terlebih dahulu untuk menentukan dosis obat yang akan diberikan, setelah itu memberi alkohol pada area leher ternak dan menginjeksi subkutan antiparasit Ivomec pada area leher. Penyuntikan dilakukan setiap 10 hari sekali. Pada metode topikal pengobatan dilakukan dengan cara menggosok keropeng pada bagian tubuh ternak yang terinfeksi scabies dengan Amitraz menggunakan dosis 10 ml Amitraz yang dihomogenkan dengan air $1.250 \mathrm{~mL}$. Prosedur pengobatan pada metode topikal yaitu dengan cara menghandling ternak, setelah itu mencelupkan kapas pada cairan Amitraz, menggosokan kapas yang telah dibasahi Amitraz pada keropeng hingga keropeng terkelupas, setelah penggosokan selesai bagian tubuh yang telah digosok diberi betadine agar tidak infeksi. Penggosokan dilakukan setiap 1 minggu sekali. Parameter yang digunakan adalah lama waktu penyembuhan dari kedua metode pengobatan yang digunakan, proses pengobatan dan kerumitan saat pelaksanaan pengobatan. Data yang diperoleh dianalisis secara deskriptif.

\section{HASIL DAN PEMBAHASAN}

Hasil pengobatan scabies dengan metode subkutan menggunakan obat antiparasit Ivomec yang diulang setiap 10 hari sekali dan untuk metode topikal dengan menggosokan larutan $V$-Traz pada keropeng yang terinfestasi scabies disajikan pada Gambar 1. dan Gambar 2.

Kondisi awal pada kambing yang terinfeksi scabies menunjukkan gejala klinis berupa keropeng pada area leher hingga punggung. Pemberian obat secara subkutan bertujuan agar obat dapat diserap secara sempurna oleh tubuh seperti yang diungkapkan oleh Aziz (2006) bahwa pemberian obat melalui suntikan ke area bawah kulit agar obat yang disuntikan di absorbsi oleh tubuh dengan pelan pelan dan berdurasi panjang (slow and sustained absorption). Injeksi subkutan dilakukan dengan menyuntikan jarum menyudut 45 derajat dari permukaan kulit lalu kulit sedikit dicubit untuk menjauhkan jaringan subkutis dari jaringan otot.

Sarcoptes scabiei menginfeksi ternak dengan menembus kulit, menghisap cairan limfe dan juga memakan sel-sel epidermis pada ternak. Kulit yang terkena infestasi tungau scabies akan membentuk luasan sisik atau keropeng yang disebabkan oleh eksudat tungau sarcoptes scabiei yang merembes keluar kulit kemudian mengering diatas kulit. Sisik ini akan menebal dan selanjutnya terjadi 
keratinasi serta proliferasi jaringan ikat. Daerah yang terinfeksi akan menjadi berkerut dan tidak rata. Rambut kulit pada daerah ini akan jarang bahkan hilang sama sekali (Subronto, 2008).

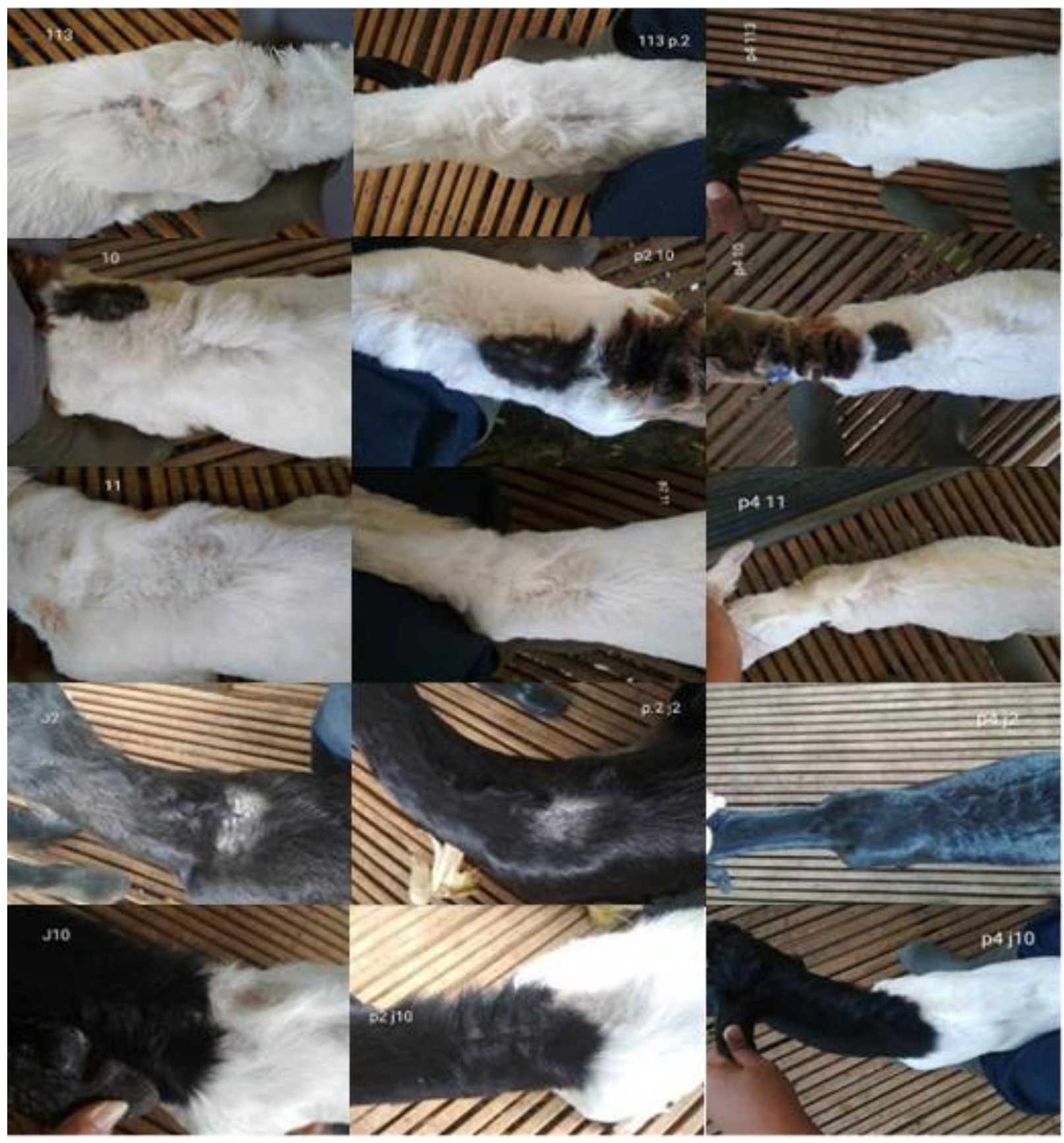

Gambar 1. Hasil pengobatan metode subkutan

Pada kambing yang terinfeksi scabies diatas menunjukkan kondisi awal pada bagian leher dan punggung terdapat penebalan kulit dan rambut disekitarnya terlihat hilang. Setelah dilakukan pengobatan injeksi Ivomec dengan pengulangan perlakuan setiap 10 hari sekali seperti yang diungkapkan oleh Ginting (2010) bahwa kambing yang terserang scabies dapat diobati dengan obat Ivomec yang diulang setiap 10 hari kemudian untuk membasmi telur dan larva yang tersisa.

Ivomec yang merupakan obat antiparasit yang mengandung Ivermectin $1 \%(10 \mathrm{mg} / \mathrm{mL})$ dan Clorunsol 10\% yang berfungsi untuk mengurangi efek post injection pada ternak. Mekanisme kerja Ivermectin di dalam tubuh adalah mengganggu aktivitas aliran ion klorida pada sistem saraf Antropoda. Preparat ini dapat terikat pada reseptor yang meningkatkan permeabilitas membran 
parasit terhadap ion klorida, sehingga akan mengakibatkan saluran klorida terbuka dan mencegah pengeluaran neurotransmitter gama amino ostinic acid. Sebagai akibatnya transmisi neuromuskuler akan terblokir dan polaritas neuron akan terganggu, sehingga menyebabkan terjadinya kematian dari parasit ternak kambing (Wardhana, 2006). Hasil pengobatan menunjukkan dengan 2 kali penyuntikan diperoleh hasil dimana gejala klinis berupa keropeng yang muncul diatas kulit dan rontok nya rambut pada area yang terinfeksi mulai terkelupas dan pada penyuntikan kedua rambut sudah mulai tumbuh dan luasan kulit yang terinfeksi sudah kembali normal. Pengobatan dengan metode ini membutuhkan waktu 20 hari hingga kambing sembuh. Adapula terapi suportif dengan memberikan vitamin B1 dan B-Kompleks untuk perawatan jaringan dan memperbaiki sistem syaraf tubuh. Terapi suportif ini didukung oleh pernyataan Wardhana (2006) dalam penanganan scabies perlu juga diperhatikan terapi suportif yaitu berupa asupan vitamin untuk perawatan jaringan tubuh.
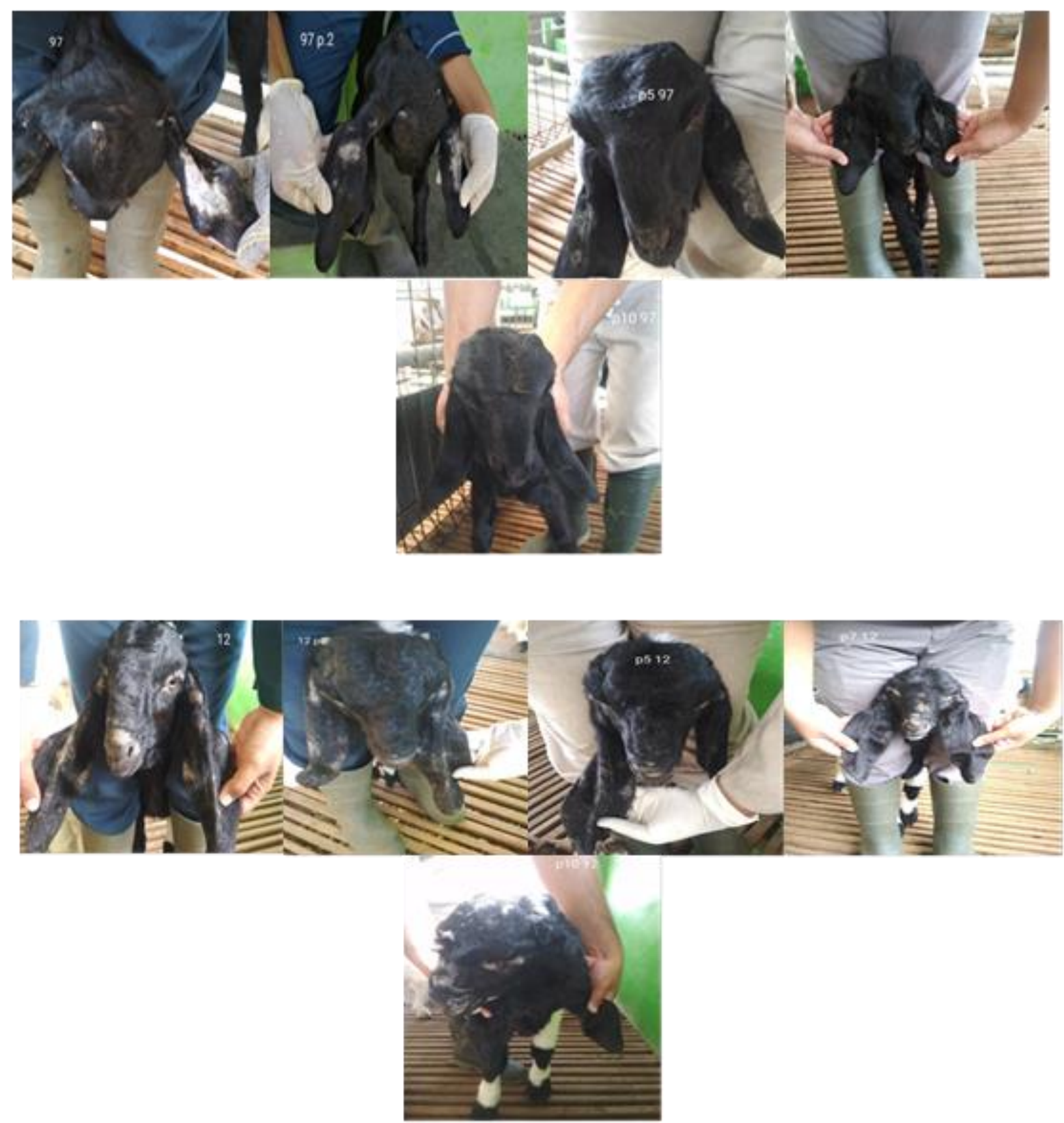

Gambar 2. Hasil pengobatan metode topikal 
Pengobatan menggunakan Ivermectin ini sangat efektif karena dalam proses pengobatannya tidak memerlukan waktu lama hanya 20 hari atau 2 kali penyuntikan dengan pengulangan penyuntikan setiap 10 hari. Kondisi ini sesuai dengan yang diungkapkan oleh Ginting (2010) bahwa kambing yang terkena Scabies diobati dengan Ivermectin yang diulang setiap 10 hari hingga sembuh. Tata cara pengobatannya pun tidak rumit karena hanya perlu menyuntikan Ivermectin secara subkutan yang tidak membutuhkan waktu lama saat mengobati kambing yang terkena Scabies. Hasil pengobatan ini didukung oleh Ginting (2010) yang menyatakan bahwa Ivermectin sangat efektif dan berhasil dalam mengobati kudis pada kambing yang disebabkan oleh tungau Sarcoptes scabiei. Pendapat ini juga didukung oleh Cholilurachman (2012) dalam penelitiannya yang mengatakan tingkat kesembuhan pengobatan dengan Ivermectin adalah 93,67\% dibandingkan menggunakan obat lain.

Pada pengobatan metode topikal terhadap kambing diatas pengaplikasiannya langsung diatas kulit yg terinfestasi dengan menggunakan obat V-Traz yang mengandung Amitraz 12,5\%. Amitraz merupakan salah satu jenis obat yang berasal dari golongan amidin. Cara kerja Amitraz adalah menghambat enzim mono amine-oxidase dan sintesa prostaglandin serta bertindak sebagai antagonis dari reseptor oktopamin. Enzim mono amine-oxidase menjadi katalisator pemecah aminnemotransmiter di dalam tubuh tungau, sedangkan oktopamin mampu meningkatkan kontraksi otot parasit (Mueller, 2004). British Veterinary Association (2005) menyebutkan Amitraz, Ivermectin dan turunannya telah digunakan oleh praktisi di seluruh dunia sebagai obat pilihan untuk mengobati scabies.

Aplikasi obat ini pada kambing dengan cara menghomogenkan terlebih dahulu Amitraz dan air dengan dosis $10 \mathrm{~mL}$ : $1.250 \mathrm{~mL}$. Setelah terhomogen handling kambing yang akan digosok dan menyiapkan kapas lalu mencelupkan secukupnya pada larutan Amitraz dan gosok pada bagian tubuh yang terinfestasi hingga keropeng atau sisik terkelupas. Waktu yang dibutuhkan untuk menggosok satu ternak yaitu 10 menit hingga keropeng benar-benar terkelupas. Jika keropeng sudah terkelupas selanjutnya memberikan betadine pada area yang telah digosok agar tidak terjadi infeksi. Pengobatan selanjutnya diulang setiap satu minggu sekali hingga sembuh seperti yang diungkapkan oleh Subronto (2008) bahwa Amitraz dapat diaplikasikan langsung di kulit dengan cara dimandikan atau digosok setiap minggu sekali. Efek samping dari penggunaan metode topikal ini adalah depresi sistem saraf dan efek sedasi sementara (British Veterinary Association, 2005).

Hasil pengobatan menujukkan perkembangan luasan kulit yang terkena Scabies pada setiap perlakuan hingga sembuh total dan kulit yang terdapat keropeng mulai normal dan sudah ditumbuhi rambut kembali membutuhkan empat kali terapi dengan lama waktu 28 hari. Pengobatan dengan metode topikal ini cukup efektif dalam mengobati Scabies hanya saja membutuhkan waktu yang agak lama dalam penanganannya. Dalam proses pengobatannya harus menggosok kulit yang terinfeksi Scabies menggunakan Amitraz yang sudah dilarutkan air hingga keropeng terlepas dari kulit. Ini membutuhkan waktu sekitar 10-15 menit pada setiap ternak tergantung pada luasan kulit yang terkena Scabies. Selain itu obat topikal ini memiliki kekurangan yaitu bisa menimbulkan rasa panas atau terbakar pada ternak yang sedang ditangani maupun pada yang menangani.

Menurut Sungkar (2016) kekurangan obat topikal adalah tidak nyaman digunakan karena terasa lengket di kulit dan memiliki efek samping rasa panas atau rasa terbakar sehingga bisa menimbulkan stress pada ternak yang sedang diobati. Oleh karena itu perlu terapi suportif berupa pemberian vitamin B-Kompleks agar kambing tidak stress dan dapat menjaga kondisi fisiologis kambing. Kondisi ini sesuai dengan pendapat Dwicipto (2010) yang mengatakan pemberian vitamin B-Kompleks dilakukan untuk memelihara sistem metabolisme tubuh, mencegah stres, menjaga kondisi fisiologis ternak sehingga produktifitasnya terjaga. 


\section{KESIMPULAN}

Pengobatan scabies yang efektif adalah menggunakan metode subkutan karena saat proses pengobatannya tidak rumit dan lama waktu penyembuhan juga lebih cepat yaitu 20 hari dibandingkan dengan metode topikal. Pengobatan metode subkutan juga dapat mengurangi tingkat stres kambing yang diakibatkan oleh rasa panas dari efek pengobatan, sehingga produktivitas ternak kambing dapat terjaga selama sakit.

\section{UCAPAN TERIMA KASIH}

Ucapan terima kasih ditujukan kepada drh. Jaya Wulandari selaku tim keswan UPT PT dan HMT Malang atas bantuannya menyediakan peralatan dan obat dan Saudara Budi Irwanto yang telah membantu saat proses pengobatan sehingga pengobatan berjalan dengan lancar.

\section{DAFTAR PUSTAKA}

Aziz, A. (2006). Kebutuhan Dasar Manusia. Jakarta: Salemba Medika.

British Veterinary Association. (2005). The Veterinary Formulary. Ed 6. London: Pharmaceutical Press.

Cholilurachman. (2012). Studi Kasus Skabies Anjing di Rumah Sakit Hewan Jakarta. Skripsi. Bogor: Institut Pertanian Bogor.

Dwicipto. (2010). Manajemen Kesehatan dan Kesejahteraan Hewan. Skripsi. Bandung: Fakultas Peternakan Universitas Padjajaran.

Ginting, N. (2010). Pengobatan kudis (Sarcoptes scabiei) dengan ivomec pada kambing. Hemera Zoa, 76(1), 50-52.

Mueller, R. S. (2004). Treatment protocols for homeopathic deals with the animal's constitutional demodicosis. Vet Dermatol, 15(2), 75-89.

Subronto. (2008). Ilmu Penyakit Ternak I (mamalia). Yogyakarta: Gadjah Mada University Press.

Sungkar, S. (2016). Skabies Etiologi, Patogenesis, Pengobatan, Pemberantasan, dan Pencegahan. Jakarta: Badan Penerbit FKUI.

Wardhana, A. H. (2006). Skabies tantangan penyakit zoonosis masa kini dan masa datang. Wartazoa. 16(1), 40-43. 